\title{
von Willebrand factor and early diabetic retinopathy: no evidence for a relationship in patients with Type 1 (insulin-dependent) diabetes mellitus and normal urinary albumin excretion
}

\author{
C.D.A.Stehouwer ${ }^{1,3}$, P.Zellenrath ${ }^{2}$, B.C.P.Polak ${ }^{2}$, G. S. Baarsma ${ }^{2}$, J.J.P.Nauta ${ }^{4}$, A. J. M.Donker ${ }^{3}$ \\ and G.J.H. den Ottolander ${ }^{1}$ \\ ${ }^{1}$ Department of Internal Medicine, Bergweg Municipal Hospital, ${ }^{2}$ Department of Ophthalmology, Erasmus University Eye Hospital, \\ Rotterdam, ${ }^{3}$ Department of Internal Medicine, ${ }^{4}$ Department of Theory of Medicine, Epidemiology and Biostatistics, Free University \\ Hospital, Amsterdam, The Netherlands
}

Summary. High plasma levels of von Willebrand factor, an indicator of endothelial cell dysfunction, have been reported in both diabetic retinopathy and nephropathy. It is unclear, however, whether von Willebrand factor is related to diabetic retinopathy in the absence of diabetic nephropathy. The relationship between retinal status and plasma von Willebrand factor concentration was investigated in a cohort of 17 patients with Type 1 (insulin-dependent) diabetes mellitus who were followed-up for a median of 42 months. The patients were examined three times. They were selected for having had normal urinary albumin excretion and no evidence of retinopathy (on fundoscopy) at the first and second examination. They were then divided into two groups, according to absence (Group A; $n=9$ ) or presence (Group B; $n=8$ ) of retinopathy on fundoscopy or fluorescein angiography at the third examination. Urinary albumin excretion remained normal in all patients. Plasma von Willebrand factor levels were similar in both groups: (median) 128 vs $123 \%, 164$ vs $132 \%$ and 159 vs $130 \%$ (first, second and third examination, respec- tively). Median changes in plasma von Willebrand factor were also similar: $+7 \mathrm{vs}+9 \%$ and +5 vs $+1 \%$ (first-second and second-third examination). Patients in whom the plasma von Willebrand factor concentration increased had higher systolic blood pressure at the third examination $(150 \pm 30 \mathrm{vs}$ $130 \pm 12 \mathrm{~mm} \mathrm{Hg}, p=0.02$ ) when compared to those in whom plasma von Willebrand factor did not increase, but were of similar age and had similar diabetes duration, retinal status, diastolic blood pressure, glycated haemoglobin and serum cholesterol concentration. These data do not support the hypothesis that increases in plasma von Willebrand factor concentration reflect retinal endothelial injury in Type 1 diabetic patients with normal urinary albumin excretion. In these patients, high or increasing plasma von Willebrand factor levels may be related to systolic blood pressure.

Key words: von Willebrand factor, endothelial function, diabetic retinopathy, blood pressure.
In the treatment of Type 1 (insulin-dependent) diabetes mellitus, prevention of micro-and macroangiopathic complications is an important, but as yet elusive, goal. Recent epidemiologicaldata suggest that patients with diabeticnephropathy often suffer from clinically important retinopathy and macroangiopathy [1-5]. The identification of microalbuminuria, i.e. a slightly elevated urinary albumin excretion rate, as a strong predictor of clinical diabetic nephropathy $[6,7]$ has allowed clinicians to identify a group of patients at high risk of developing severe complications of diabetes thereby targeting these patients for intensified treatment. It has become clear, however, that microalbuminuria constitutes incipient diabetic nephropathy [7]. Therefore, it may be useful to define risk indicators of diabetic complication development at an earlier stage, i. e. when urinary albumin excretion is normal.

Although diabetic nephropathy appears linked to severe retinopathy [5], hypertension [5] and cardiovascu- lar disease [3, 4], the nature of this linkage is not clear. It has been suggested that dysfunction of vascular endothelium may represent the pathophysiological basis for these epidemiological observations [8,9], being involved in the development of proteinuria [10], retinopathy [11], hypertension [12] and atherosclerosis [13]. Vascular endothelium is intimately involved in the regulation of various processes, e.g., haemostasis, fibrinolysis, vasomotor control and vascular permeability, all of which may be relevant to the pathogenesis of diabetic complications. Therefore, markers of endothelial dysfunction are candidate risk indicators for the development of such complications. von Willebrand factor (vWF), a glycoprotein important in primary haemostasis and synthesised mainly by endothelial cells, may serve as such a marker $[8,14,15]$, high plasma levels indicating endothelial injury. In support of this hypothesis, the development of incipient diabetic nephropathy was shown to be paralleled by increases in plasma 
vWF concentration [16]. It is unclear, however, whether development of diabetic retinopathy is similarly accompanied by increases in plasma vWF. To investigate this, we studied the relationship between retinal status and plasma vWF level in patients with Type 1 diabetes and normal urinary albumin excretion.

\section{Subjects and methods}

\section{Cohort study}

As part of a prospective study attempting to define the relationship between development of complications of diabetes and markers of endothelial dysfunction, 65 patients with Type 1 diabetes (fasting Cpeptide level less than $0.01 \mathrm{nmol} / \mathrm{l}$ ) were selected, as previously described [16]. Informed consent was given for the following studies by all patients. Clinical and laboratory data, as detailed below, were obtained at three time points: between June, 1985, and August, 1989 ('first examination'), between June, 1987, and March, 1990 ('second examination') and again between January and April, 1990 ("third examination'). The first and second examination were completed in 59 patients, 21 of whom had an abnormal urinary albumin excretion rate. Patients were invited for the third examination when, at the second examination, they had had normal urinary albumin excretion, no diabetic retinopathy on ophthalmoscopy, fair $\left(\mathrm{HbA}_{1 \mathrm{c}}<8.5 \%\right)$ glycaemic control and used no medication other than insulin. $\mathrm{Pa}-$ tients in poor glycaemic control were excluded to avoid a possible confounding effect on plasma levels of vWF [17].

\section{Clinical and laboratory studies [16]}

At each examination, we recorded age, diabetes duration, body mass index, blood pressure, insulin dose, current smoking habits and current medication. Blood pressure (diastolic phase V) was measured twice after $15 \mathrm{~min}$ of supine rest using a standard sphygmomanometer with an appropriately sized cuff. In the six weeks prior to each examination, all patients collected three or more urine samples for determination of urinary albumin. (Data were collected without knowledge of the patient's retinal status or plasma vWF level.) After an overnight fast, blood was drawn from an antecubital vein for measurement of glucose, vWF antigen and glycated haemoglobin. Glucose was determined using a glucose oxidase method. vWF antigen was measured by immunoelectrophoresis [18], using a polyclonal antibody. The intra- and interassay variation of this method are 4.1 and $8.7 \%$, respectively. Care was taken to avoid increases in vWF associated with hypoglycaemia, exercise and venous occlusion, as previously described [16]. In our experience, the within-person day-to-day variability of plasma vWF antigen concentration is thus reduced to approximately $10 \%$ (unpublished observation). Levels of and changes in vWF are expressed as percentages of normal pooled plasma, the activity of which is defined as 100\% (normal range in our laboratory, $50-150 \%$ ). An increase in plasma concentration of vWF is defined as a change of more than $+10 \%$ (in view of the estimated within-person day-to-day variability). Glycated haemoglobin was measured with a spectrophotometric assay using reagents obtained from Bio-Rad (Richmond, Va., USA). Two assays were used, for $\mathrm{HbA}_{1}$ and $\mathrm{HbA}_{1 \mathrm{c}}$, respectively. According to the manufacturer and in agreement with our own observations, glycated haemoglobin measured by the latter assay is comparable to $75-80 \%$ of values obtained by the former method. Therefore, all measurements are reported as glycated haemoglobin, using 0.775 and 1.0 as converting factors. Thus, the normal range in our laboratory for glycated haemoglobin is $3.5-6.5 \%$. Serum cholesterol concentration was determined with an enzymatic technique (Boehringer Mannheim, Mannheim, FRG). Urinary albumin concentration was determined by radioimmunoassay (Pharmacia AB, Uppsala, Sweden).
The sensitivity of this method is $0.4 \mathrm{mg} / \mathrm{l}$. On the basis of the mean urinary albumin excretion rate in at least three consecutive 4-h morning urine collections $[6,7]$, patients were classified as having normal $(<15 \mu \mathrm{g} / \mathrm{min}[19])$ or increased urinary albumin excretion.

\section{Ophthalmologicalstudies}

At the first and second examination, the ocular fundus was examined by an ophthalmologist after dilatation of the pupils and classified as normal (less than 3 microaneurysms), background retinopathy or proliferative retinopathy. At the third examination ophthalmoscopy was repeated by two ophthalmologists. In addition, fluorescein angiograms were obtained after intravenous injection of $5 \mathrm{ml}$ of a $10 \%$ solution of sodium fluorescein and assessed by two ophthalmologists. All ophthalmological studies were done without knowledge of the patients'vWF plasma levels.

\section{Statistical analysis}

To assess the relationship between retinal status and plasma $\mathrm{vWF}$ level, the patients were divided into two groups according to the $a b$ sence (Group A) or the presence (Group B) of retinopathy (at the third examination) and compared with regard to vWF levels. The statistical power to detect differences between the groups with $\alpha=0.05$ depends on the number of patients in each group, the level of difference to be detected and the variance in the variable measured. For our investigation, the power to detect a $50 \%$ difference [11] in plasma vWF concentration between the groups was $50 \%$. The power to detect a $15 \%$ difference in changes in plasma vWF concentration, however, was $96 \%$ between the second and third examination. Thus, the overall power to detect a relationship between retinal status and plasma vWF concentration appears adequate.

To assess the relationship between endothelial dysfunction (as reflected by plasma vWF levels) and clinical data, the patients were divided into two groups according to the absence (Group 1) or the presence (Group 2) of an increase in plasma vWF levels between the first and second examination and compared with regard to clinical data. We were particularly interested in the relation between vWF and other possible determinants of endothelial injury (age, diabetes duration, glycated haemoglobin, smoking habits, serum cholesterol and blood pressure).

Standard parametric and non-parametric statistical testing was used as appropriate. All testing was two-sided. $p$ values $<0.05$ were considered statistically significant.

\section{Results}

From the original cohort, all 17 patients who were eligible at the second examination agreed to participate in the third. Compliance with the study protocol [16] was excellent. There were only two smokers among the patients; this factor was, therefore, omitted from further analysis. At the time of the third examination, none of the patients had clinical evidence of macrovascular complications or used any medication other than insulin. All had normal urinary albumin excretion. Blood glucose levels at the time of blood sampling for vWF measurements varied between 3.6 and $15.7 \mathrm{mmol} / \mathrm{l}$. Retinal abnormalities were observed on fundoscopy in six of 17 patients. These abnormalities were generally mild and consisted of microaneurysms and, in five patients, small haemorrhages. Fluorescein angiograms, obtained in 16 of 17 patients, 
Table 1. Clinical and laboratory data of a cohort of 17 patients with Type 1 (insulin-dependent) diabetes mellitus examined three times, according to the presence of retinopathy ${ }^{\mathrm{a}}$

\begin{tabular}{lll}
\hline & $\begin{array}{l}\text { Group A } \\
\text { Retinopathy } \\
\text { absent }\end{array}$ & $\begin{array}{l}\text { Group B } \\
\text { Retinopathy } \\
\text { present }\end{array}$ \\
\hline$n$ (men/women) & $9(4 / 5)$ & $8(4 / 4)$ \\
$\begin{array}{l}\text { Follow-up (months) } \\
\text { 1st-2nd examination }\end{array}$ & $25 \pm 12$ & $30 \pm 12$ \\
2nd-3rd examination & $15 \pm 5$ & $14 \pm 3$ \\
Age (years) & $49 \pm 18$ & $44 \pm 11$ \\
Diabetes duration (years) & $8(2-35)$ & $15(11-30)^{b}$ \\
Glycated haemoglobin $(\%)$ & & \\
1st examination & $7.7 \pm 0.9$ & $8.7 \pm 1.1$ \\
2nd examination & $7.1 \pm 0.8$ & $6.7 \pm 1.1$ \\
3rd examination & $6.8 \pm 0.7$ & $6.6 \pm 1.0$ \\
Blood pressure (mm Hg) & & \\
1st examination & $151 / 88 \pm 26 / 7$ & $126 / 79 \pm 15 / 11^{\mathrm{c}}$ \\
2nd examination & $141 / 84 \pm 22 / 7$ & $130 / 81 \pm 16 / 9$ \\
3rd examination & $143 / 86 \pm 16 / 5$ & $134 / 81 \pm 14 / 6$ \\
Serum cholesterol (mmol/1) & & \\
1st examination & $6.3 \pm 0.8$ & $5.9 \pm 0.6$ \\
2nd examination & $6.4 \pm 0.7$ & $6.0 \pm 0.6$ \\
3rd examination & $6.3 \pm 0.8$ & $5.7 \pm 0.6$ \\
von Willebrand factor $(\%)$ & & \\
1st examination & $128(98-210)$ & $123(87-129)$ \\
2nd examination & $164(69-206)$ & $132(92-274)$ \\
3rd examination & $159(82-210)$ & $130(90-270)$ \\
change 1st-2nd & $+7(-33$ to +102$)$ & $+9(-18$ to +145$)$ \\
change 2nd-3rd & $+5(-6$ to +13$)$ & $+1(-8$ to +20$)$ \\
\hline & &
\end{tabular}

Data are given as mean \pm SD or as median (range), unless otherwise indicated. a as determined at the third examination (see Subjects and methods); ${ }^{b} p=0.02 ;{ }^{\mathrm{c}} p=0.03$ for difference in systolic blood pressure between groups $\mathrm{A}$ and $\mathrm{B}$

were abnormal in seven patients. In the patient in whom angiography was not performed, fundoscopy had shown several small retinal haemorrhages (for the statistical analysis, angiography in this patient was considered abnormal). Retinal abnormalities observed on angiography were: dilated perimacular capillaries and microaneurysms in all patients and small retinal haemorrhages in four patients.

\section{Retinal status and plasma $v$ WF level}

vWF and presence of retinopathy: At the third examination, retinopathy was absent (on both fundoscopy and angiography) in nine patients (Group A) and present in eight (Group B). Table 1 shows clinical and laboratory data. The groups were comparable with regard to sex ratio, follow-up duration, age, glycated haemoglobin, serum cholesterol concentration and diastolic blood pressure. In Group B, systolic blood pressure was lower at the first examination $(151 \pm 26$ vs $126 \pm 15 \mathrm{~mm} \mathrm{Hg}$, $p=0.03$ ), but this difference was less clear (and non-significant) at the subsequent examinations. Diabetes duration was longer in Group B (median 8 vs 15 years, $p=0.02$ ). No differences were observed between the groups with regard to absolute levels of or changes in plasma vWF at any of the three examinations (Table 1).

vWF and development of retinopathy: Angiograms were not obtained at the first two examinations. Development of retinopathy can therefore be judged only on the basis of the results of fundoscopy. At the third examination, fundoscopic evidence of retinopathy was present (i. e. had developed) in six patients and absent in eleven. The plasma levels of vWF were not significantly different between these groups, nor were changes in the plasma vWF levels. vWF levels (median and range) were 119 (87-129) and $125(98-210) \%$ at the first examination, 132 (92-274) and $164(69-206) \%$ at the second examination and $130(90-270)$ and $159(82-210) \%$ at the third examination, respectively. Changes in vWF were $+9(+5$ to $+145)$ and $+7(-35$ to +102$) \%$ between the first and second examination and $-3(-8$ to +20$)$ and $+5(-6$ to $+18) \%$ between the second and third examination.

\section{Changes in plasma $v W F$ level and clinical characteristics}

Between the first and second examination, plasma vWF levels remained stable or decreased in 10 patients (from [median] 123 to $121 \%$; Group 1) and increased (from [median] 125 to $200 \%$ ) in seven (Group 2). Table 2 shows clinical and laboratory data of these two groups. The groups were not significantly different regarding sex ratio, follow-up duration, age, diabetes duration, glycated haemoglobin, serum cholesterol concentration and urinary albumin excretion. Retinal status, too, was similar in both groups. Abnormalities on fundoscopy were present in four of ten patients in Group 1 and in two of seven patients in Group 2. The severity of the retinopathy was not different between the groups. Angiography was abnormal in four of nine patients in Group 1 and in three of seven patients in Group 2, and again the abnormalities observed were of similar severity. Systolic blood pressure tended to be higher in Group 2, a difference that became significant at the third examination $(133 \pm 14$ vs $149 \pm 34[p=0.21]$, $128 \pm 13$ vs $146 \pm 23 \quad[p=0.05]$ and $132 \pm 11$ vs $149 \pm 17 \mathrm{mmHg}[p=0.02]$, respectively; Table 2). Diastolic pressures, however, were not significantly different. Correlation analysis disclosed no significant correlation between absolute levels of, or changes in, blood pressure and plasma vWF. Finally, the difference in vWF level at the third examination (median, 118 vs $205 \%$ ) was highly significant $(p=0.001)$, indicating that intra-individual changes in plasma vWF between the second and third examination were generally small and not different between the groups (median, +4 vs $+5 \%, p=0.41$; Table 2).

\section{Discussion}

In patients with Type 1 diabetes and normal urinary albumin excretion, retinal status and plasma vWF concentration do not appear related, nor do changes in plasma vWF level predict the presence or development of early diabetic retinopathy. 
Table 2. Clinical and laboratory data of a cohort of 17 patients with Type 1 (insulin-dependent) diabetes mellitus examined three times, according to an increase in plasma von Willebrand factor level ${ }^{\mathrm{a}}$

\begin{tabular}{|c|c|c|}
\hline & $\begin{array}{l}\text { Group } 1 \\
\text { No increase in } \\
\text { von Willebrand } \\
\text { factor }\end{array}$ & $\begin{array}{l}\text { Group } 2 \\
\text { Increase in } \\
\text { von Willebrand } \\
\text { factor }\end{array}$ \\
\hline$n$ (men/women) & $10(5 / 5)$ & $7(3 / 4)$ \\
\hline $\begin{array}{l}\text { Follow-up (months) } \\
\text { 1st-2nd examination } \\
\text { 2nd-3rd examination }\end{array}$ & $\begin{array}{l}24 \pm 11 \\
14 \pm 4\end{array}$ & $\begin{array}{l}32 \pm 12 \\
15 \pm 3\end{array}$ \\
\hline Age (years) & $46 \pm 12$ & $47 \pm 19$ \\
\hline Diabetes duration (years) & $13(11-47)$ & $12(2-35)$ \\
\hline $\begin{array}{l}\text { Glycated haemoglobin }(\%) \\
\text { 1st examination } \\
\text { 2nd examination } \\
\text { 3rd examination }\end{array}$ & $\begin{array}{l}8.1 \pm 1.0 \\
6.9 \pm 0.8 \\
6.8 \pm 0.8\end{array}$ & $\begin{array}{l}8.2 \pm 1.3 \\
6.8 \pm 1.1 \\
6.7 \pm 0.9\end{array}$ \\
\hline $\begin{array}{l}\text { Blood pressure }(\mathrm{mm} \mathrm{Hg}) \\
\text { 1st examination } \\
\text { 2nd examination } \\
\text { 3rd examination }\end{array}$ & $\begin{array}{l}133 / 84 \pm 14 / 6 \\
128 / 80 \pm 13 / 4 \\
130 / 84 \pm 12 / 4\end{array}$ & $\begin{array}{l}149 / 84 \pm 34 / 14 \\
146 / 86 \pm 23 / 10^{b} \\
150 / 86 \pm 30 / 8^{c}\end{array}$ \\
\hline $\begin{array}{l}\text { Serum cholesterol }(\mathrm{mmol} / \mathrm{l}) \\
\text { 1st examination } \\
\text { 2nd examination } \\
\text { 3rd examination }\end{array}$ & $\begin{array}{l}6.1 \pm 0.8 \\
6.2 \pm 0.6 \\
6.1 \pm 0.8\end{array}$ & $\begin{array}{l}6.1 \pm 0.8 \\
6.2 \pm 0.7 \\
6.0 \pm 0.7\end{array}$ \\
\hline $\begin{array}{l}\text { von Willebrand factor }(\%) \\
\text { 1st examination } \\
\text { 2nd examination } \\
\text { 3rd examination } \\
\text { change } 1 \text { st-2nd } \\
\text { change } 2 \text { nd-3rd }\end{array}$ & $\begin{array}{l}123(87-210) \\
120(69-186) \\
118(82-190) \\
-1(-33 \text { to }+9) \\
+4(-8 \text { to }+13)\end{array}$ & $\begin{array}{l}125(98-161) \\
200(164-274)^{\mathrm{d}} \\
205(159-270)^{\mathrm{e}} \\
59(39 \text { to } 145)^{\mathrm{d}} \\
+5(-6 \text { to }+20)\end{array}$ \\
\hline $\begin{array}{l}\text { Urinary albumin excretion }(\mu \mathrm{g} / 1 \\
\text { 1st examination } \\
\text { 2nd examination } \\
\text { 3rd examination }\end{array}$ & $\begin{array}{l}\min ) \\
6.1(2.4-12.9) \\
7.4(3.6-14.2) \\
6.8(3.9-14.3)\end{array}$ & $\begin{array}{l}6.4(3.1-14.2) \\
7.2(3.9-13.6) \\
6.9(4.2-13.9)\end{array}$ \\
\hline Fundoscopy ${ }^{f}$ (No. [\%] normal) & $6(60 \%)$ & $5(71 \%)$ \\
\hline $\begin{array}{l}\text { Fluorescein angiography } \\
\text { (No. }[\%] \text { normal) }\end{array}$ & $5(55 \%)$ & $4(57 \%)$ \\
\hline
\end{tabular}

Data are given as mean \pm SD or as median (range), unless otherwise indicated. a between the first and second examination (see Subjects and methods); ${ }^{\mathrm{b}} p=0.05$ and ${ }^{\mathrm{c}} p=0.02$ for difference in systolic blood pressure between groups 1 and 2 ; ${ }^{\mathrm{d}}$ not tested; ${ }^{\mathrm{e}} p=0.001 ;{ }^{\mathrm{f}}$ at the third examination (see Subjects and methods)

It has repeatedly been shown that measures of endothelial function tend to be abnormal in patients suffering from diabetic microangiopathy $[8,9,11,15,16,20,21]$. The plasma level of $\mathrm{vWF}$ is thought to reflect endothelial function [14], and, not surprisingly, the plasma vWF level is often reported as elevated in patients with diabetes, especially when microangiopathy is present [8]. It is not clear, however, whether diabetic retinopathy or nephropathy is the more important determinant of high vWF levels in these patients. In earlier studies [11] microalbuminuria (i.e., incipient diabetic nephropathy as defined between 1982-1984 [6, 7]) was not excluded and may have confounded the results. In a cross-sectional study addressing this issue, Jensen found elevated vWF levels in patients with microalbuminuria, but no independent relation of $v W F$ with retinopathy as determined by fundoscopy [15]. His conclusions are supported by the present study, which employed both fundoscopy and the more sensitive fluorescein angiography in patients in whom urinary albumin excretion was normal. Therefore, it appears that diabetic nephropathy, and not retinopathy, is the most important determinant of high vWF levels $[15,16]$. This conclusion is consistent with epidemiological data showing that patients with diabetic nephropathy often have hypertension and cardiovascular disease [2-5], conditions that may be pathogenetically related to endothelial dysfunction [12,13]. In fact, systolic blood pressure was significantly higher in the present study in those patients in whom plasma levels of vWF increased. These considerations do not imply that endothelial dysfunction is not important in the pathogenesis of diabetic retinopathy; a large body of evidence to the contrary exists [22]. High vWF levels, however, may not directly reflect dysfunction of retinal endothelium, as opposed to endothelium elsewhere in the body. Moreover, as retinal blood flow represents only a small part of total body blood flow, it appears a priori unlikely that high systemic vWF levels should be determined by increased production by retinal endothelium. Note, however, that the selection criteria employed here necessarily restrict the study's relevance to a specific category of patients, i. e. well-controlled patients with early retinopathy; no conclusions can be drawn with regard to more advanced stages of retinal disease.

How, then, may the changes in plasma vWF levels observed in our patients, who had normal urinary albumin excretion, be explained? vWF levels may be influenced by age [23] and, possibly, by glycaemic control [16, 17, 24], but, as these factors were similar in patients with and without increases in plasma vWF, they are an unlikely explanation for the differences in vWF level changes observed. As diabetic nephropathy is associated with both high vWF concentrations and a high incidence of cardiovascular disease $[3-5,15,16]$, and as atherosclerosis in non-diabetic patients is also associated with high vWF levels [25, 26], we propose that diabetic patients with normal urinary albumin excretion and high or increasing vWF levels have clinically silent endothelial dysfunction, which may indicate an increased risk of developing nephropathy and cardiovascular disease. In this regard, the higher systolic blood pressures observed in patients with increases in plasma vWF concentration may indicate increased arterial stiffness, which may be due to atherosclerosis [27]. Alternatively, higher blood pressure may cause endothelial injury. Obviously, further prospective studies are needed to test these hypotheses.

In conclusion, we found no relationship between changes in plasma vWF level (as an indicator of endothelial function) and retinal status in patients with Type 1 diabetes and normal urinary albumin excretion. Thus, increases in plasma vWF concentration, if indeed reflecting endothelial dysfunction, are probably not influenced by early retinal endothelial damage. Increases in the plasma vWF level were found to be associated with higher systolic blood pressures. As a role for endothelial dysfunction in the pathogenesis of vascular complications of diabetes appears pathophysiologically plausible, measuring markers of endothelial dysfunction may be clinically relevant. vWF may be one such marker; presence [15] and develop- 
ment [16] of microalbuminuria are associated with increases in the plasma level of vWF. Further studies are now warranted to investigate whether high or increasing vWF levels precede and predispose to the development of microalbuminuria.

Acknowledgements. We thank Dr. W.H.L.Hackeng for measuring urinary albumin and Dr. R. J. Heine for helpful discussions.

\section{References}

1. Andersen AR, Sandahl Christiansen J, Andersen JK, Kreiner S, Deckert T (1983) Diabetic nephropathy in Type 1 (insulindependent) diabetes: an epidemiological study. Diabetologia 25: 496-501

2. Krolewski AS, Warram JH, Rand LI, Kahn CR (1987) Epidemiologic approach to the etiology of Type 1 diabetes mellitus and its complications. N Engl J Med 317: 1390-1398

3. Jensen T, Borch-Johnsen K, Kofoed-Enevoldsen A, Deckert T (1987) Coronary heart disease in young Type 1 (insulin-dependent) diabetic patients with and without diabetic nephropathy: incidence and risk factors. Diabetologia 30: 144-148

4. Borch-Johnsen K, Kreiner S (1987) Proteinuria - a predictor of cardiovascular mortality in insulin-dependent diabetes mellitus. Br Med J 294: 1651-1655

5. Parving HH, Hommel E, Mathiesen Eet al. (1988) Prevalence of microalbuminuria, arterial hypertension, retinopathy and neuropathy in patients with insulin-dependent diabetes. $\mathrm{Br} \mathrm{Med}$ J 296: 156-160

6. Viberti GC, Wiseman MJ (1986) The kidney in diabetes: significance of the early abnormalities. Clin Endocrinol Metab 15:753782

7. Mogensen CE (1987) Microalbuminuria as a predictor of clinical diabetic nephropathy. Kidney Int 31: 673-689

8. Porta M, La Selva M, Molinatti P, Molinatti GM (1987) Endothelial cell function in diabetic microangiopathy. Diabetologia 30 : $601-609$

9. Deckert T, Feldt-Rasmussen B, Borch-Johnsen K, Jensen T, Kofoed-Enevoldsen A (1989) Albuminuria reflects widespread vascular damage. The Steno hypothesis. Diabetologia 32:219-226

10. Kanwar YS (1984) Biophysiology of glomerular filtration and proteinuria. Lab Invest 51:7-21

11. Porta M, Townsend C, Clover GM et al. (1981) Evidence for functional endothelial cell damage in early diabetic retinopathy. Diabetologia 20: 597-601

12. Vane JR, Anggård EE, Botting RM (1990) Mechanisms of disease: regulatory functions of the vascular endothelium. $\mathrm{N}$ Engl Med 323:27-36

13. Ross R (1986) The pathogenesis of atherosclerosis: an update. $N$ Engl J Med 314: 488-500
14. Editorial (1988) Factor VIII-related antigen and vasculitis. Lancet I: $1203-1204$

15. Jensen T (1989) Increased plasma level of von Willebrand factor in type 1 (insulin-dependent) diabetic patients with incipient nephropathy. Br Med J 298: 27-28

16. Stehouwer CDA, Stroes ESG, Hackeng WHL, Mulder PGH, den Ottolander GJH (1991) von Willebrand factor and development of diabetic nephropathy in insulin-dependent diabetes mellitus. Diabetes 40: 971-976

17. Vukovich TC, Schernthaner G, Knöbi PN, Hay U (1989) The effect of near-normoglycemic control on plasma factor VIII/von Willebrand factor and fibrin degradation products in insulin-dependent diabetic patients. J Clin Endocrinol Metab 69:84-89

18. Laurell CB (1966) Quantitative estimation of proteins by electrophoresis in agarose gel containing antibodies. Anal Biochem 15: $45-52$

19. Stehouwer CDA, Fischer HRA, Hackeng WHL, den Ottolander GJH (1990) Identifying patients with incipient diabetic nephropathy: should 24-hour urine collections be used? Arch Intern Med 150: 373-375

20. Feldt-Rasmussen B (1986) Increased transcapillary escape rate of albumin in Type 1 (insulin-dependent) diabetic patients with microalbuminuria. Diabetologia 29: 282-286

21. Jensen T, Bjerre-Knudsen J, Feldt-Rasmussen B, Deckert T (1989) Features of endothelial dysfunction in early diabetic nephropathy. Lancet I: 461-463

22. Merimee TJ (1990) Diabetic retinopathy: a synthesis of perspectives. N Engl J Med 322: 978-983

23. Bloom AL (1979) The biosynthesis of factor VIII. Clin Haematol 8: 53-77

24. Mordes DB, Lazarchick J, Collwell JA, Sens DA (1983) Elevated glucose concentrations increase factor VIIIR:AG levels in human umbilical vein endothelial cells. Diabetes 32: 876-878

25. Bern MM, Cassani MP, Horton J, Rand L, Davis G (1980) Changes of fibrinolysis and factor VIII coagulant, antigen, and ristocetin cofactor in diabetes mellitus and atherosclerosis. Thromb Res 19: 831-839

26. Jansson JH, Nilsson TK, Johnson O (1991) von Willebrand factor in plasma: a novel risk factor for recurrent myocardial infarction and death. Br Heart J 66: 351-355

27. O'Rourke M (1990) Arterial stiffness, systolic blood pressure, and logical treatment of arterial hypertension. Hypertension 15 : 339-347

Received: 8 November 1991

and in revised form: 27 January 1992

Dr. C.D.A.Stehouwer

Department of Internal Medicine

Free University Hospital

P.O. Box 7057

NL-1007 MB Amsterdam

The Netherlands 